\section{Jane Dalgarno BSc, BADN President}

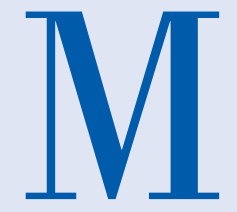

arch has been another busy month in my role as BADN President. Plans are well under way for the forthcoming Dentistry Show and BADN's involvement with the Dental Nurse Forum, which I will be chairing. I am looking forward to meeting as many dental nurses as possible there this month [April].

I attended meetings with a number of awarding bodies for dental nurse education. I am keen to ensure BADN is influential in this sector and the routes that dental nurses can take both pre and post registration.

These awarding bodies will have promotional stands at BADN Conference in October and will have a series of articles in the British Dental Nurses' Journal.

It was with interest that I met with John Milne, National Dental Advisor for the Care Quality Commission (CQC) to discuss issues facing dental nurses in their role as CQC Registered Managers. The CQC will randomly inspect $10 \%$ of dental practices, but also those where concerns have been expressed. A Provider Handbook is available to advise practices before inspections. Safeguarding and cross infection appear to be the main areas of non-compliance. The CQC welcome both good and bad feedback, following inspection. Further information on the CQC can be found at http://www.cqc.org. uk/ and www.badn.org.uk.

I was delighted to have been approached by the British Society of Periodontology (BSP) seeking support for their upcoming campaign and their National Gum Awareness Day on 12 May. The Society recognises the important role the dental nurse plays in prevention and will have resources available for promoting this campaign with patients and colleagues. The BADN will feature this in the Spring British Dental Nurses' Journal, on our website and in other promotional material.

Finally, if I could remind you to participate in the survey that the BADN is conducting in relation to the demographic profile of the dental nurse. This is available at: www.badn.org.uk. \footnotetext{
CENTRIC APPROACH

The British Society of Dental Hygiene and

I Therapy (BSDHT) has unveiled their new

I website which makes it easier for the public

I to find a member in their area.

Patients are now able to search from

BSDHT members practising near them

through the 'Find a Dental Hygienist/

I Therapist' feature which is central to the I new website.

Michaela ONeill, President of the BSDHT, said: 'This is a brand new feature, and one

which we are encouraging everyone to

get involved with. By becoming part of

I the BSDHT members have an incredible

I opportunity to grow their public presence

and boost their patient lists.
}

NEW BSDHT WEBSITE HAS PATIENT

'One of the biggest issues affecting oral health in the UK today is the ability for the public to access services; by giving our website a patient centric approach we hope to address this and make people more comfortable about visiting their dental team.'

The new website also offers many other benefits to members including access to the latest goings on in dentistry through the improved news section; a live Twitter feed; and information about the upcoming Oral Health Conference and Exhibition in Belfast later this year.

Go to www.bshdt.org.uk to visit the new website and find out more about the conference.

\section{OUTSTANDING CONTRIBUTION}

RAF Warrant Office Pam Daley has been awarded the 2016 BADN Outstanding Contribution to Dental Nursing Award.

Pam joined the Royal Air Force (RAF) in 1986

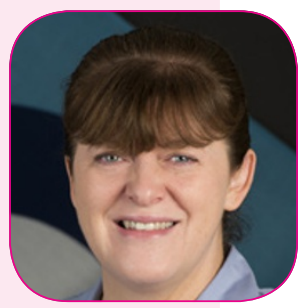
and has been a clinical dental nurse, practice manager, regional practice manager and Head of Dental Nurse training for Defence. She also founded, and was the first Secretary of, the BADN Armed Forces Group.

In 2010 she was appointed as a NEBDN examiner and became a Trustee in 2015. Pam has been a presiding examiner for the Board and is also a member of the NEBDN Quality Assurance committee.

Pam is currently a serving Warrant Officer and is the lead dental nurse of the RAF, looking after the welfare and careers of all RAF dental nurses.

The award will be presented to Pam at the BDA Honours and Award Gala Dinner on 28 May at the Midland Hotel, Manchester.

\section{DIARY DATES}

Event: $7^{\text {th }}$ DCP Symposium

Host: Dental Postgraduate Section of

the Wales Deanery in collaboration with The Royal College of Surgeons Edinburgh

Date: 27 May 2016

Location: Marriott Hotel, Cardiff

Further details: email liddingtonke@

cf.ac.uk or hayeskj@cardiff.ac.uk

Event: $2^{\text {nd }}$ Dental Practice Manager Conference

Host: Forum Training

Date: 22 June 2016

Location: Thistle City Barbican, London Further details: http://www.

forumbusinesstraining.co.uk/education/ event/339-dental-practice-managerconference-2016-Iondon-22ndjune 